\section{0th Birthday Symposium for Professor C. Zener Von Hippel Winner}

W. W. Mullins

Chairman,

Symposium Organizing Committer

A symposium was held in honor of Professor Clarence Zener on the occasion of his 80 th birthday to recognize the impact of his work on many fields of science and engineering. The symposium was held at Carnegie-Mellon University (Pittsburgh, PA) on November 23, 1985. The symposium was attended by approximately 100 scientists and engineers from many fields and many parts of the world. At the banquet celebration, H. A. Simon spoke on scientific creativity. Papers were presented by $F$. Seitz, C. A. Wert, J. Weertman, M. Hillert, R. J. Duffin and E. L. Peterson, and by the guest of honor, $C$. Zener, who has developed a new theory of strong electrolytes. These papers, and one prepared later by $W$. J. Carr, Jr. and M. Garbuny, will appear in the Journal of Applied Physics.

The symposium papers demonstrated the impact of Zener's pioneering work on metallurgy and materials science, solidstate physics, engineering, and mathematics. This impact derives partly, I believe, from the simplicity with which the basic physics underlying key phenomena is exposed in Zener's work, and partly from the creative influence of his personality on his colleagues. In many cases he has originated entire fields of investigation (e.g. internal friction, geometric programming). Spanning the full range of Zener's scientific contributions, however, proved to be an elusive goal for the symposium. Not covered in any detail, for example, was his work in atomic physics and his theory of dielectric breakdown.

Zener received his BS degree from Stanford in 1926 and his PhD from Harvard in 1929. During the following five years he was awarded fellowships that took him to several universities in Germany, to Princeton University and to Bristol University, England. He has held academic posts at Washington University (St. Louis, MO), City College of New York, Washington State University, University of Chicago, Texas A\&M University and CarnegieMellon University, where he has been since 1968. He was with the Watertown Arsenal (Maryland) for three years during World War II, and later with the research laboratories of Westinghouse Elect ric Corporation in Pittsburgh for 15 years.

Zener has received the following awards: Exceptional Civilian Service Award (1946) of the War Department; Bingham Award (1957) of the Society of Rheology; Wetherill Medal (1959) of the Franklin Institute;
Albert Souveur Achievement Award (1965) of the American Society for Metals; Gold Medal (1974) of the American Society for Metals; and the Von Hippel Award (1982) of the Materials Research Society. He is a fellow of the American Physical Society and a member of the National Academy of Sciences.

Professor Zener had the following remarks about his career:

The two men who had the greatest influence on my work are J. R. Oppenheimerand P. W. Bridgeman. I was fortunate to spend a whole day with Oppenheimer in 1930. I recognized the impossibility of competing with men of his caliber in developing the fundamental laws of physics, and that 1 must be content with explaining observed phenomena in terms of known laws. Bridgeman imparted to me his passion for thermodynamics. It was this insight he provided that gave me the clue to a wide range of physical problems. My work at Watertown Arsenal taught me that fackling practical problems exposes one to basic physical problems that have not been discussed in the scientific journals, and therefore asts as a powerful catalyst.

I have always derived pleasure from recognizing areas that have lain outside the mainstream of physics research, but that obviously can be understood by the application of physical principles. I would immerse myself in these studies for several years until they attracted other physicists.

In the sixties I had been interested in environmental problems, but it was not until l came to CarnegieMellon University that I had the leisure to give more than occasional attention to such problems. I decided to search for an economic way of utilizing the renewable work potential in our environment. In this endeavor I soon recognized how little we physicists knew about water. I hope my present work will lend other physicists to take the plunge.

\section{Frontiers of Electron Microscopy in Materials Science}

The first conference in a series on "Frontiers of Electron Microscopy in Materials Science" was held April 20-23, 1986 at Argonne National Laboratory (Illinois). The conference was sponsored by the Materials Science and Technology Division at Argonne, the Chicago Section of The Metallurgical Society of AIME, and the Midwest Society of Electron Microscopists. The conference was attended by more than 225 participants including 20 from foreign countries. Of the participants, $56 \%$ were from universities, $31 \%$ from industry, and $13 \%$ from national laboratories. Of the university participants, $30 \%$ were graduate students from universities around the United States.

Plenary lectures acquainted the conference participants with state-of-the-art techniques in electron microscopy. These lectures were followed by a series of presentations on advanced topics which gave examples of how these techniques have been applied to problems in materials science. Each contributed oral presentation was also associated with a poster. In this way, discussions on contributed talks continued beyond the lecture hall. The conference proceedings, including more than 50 papers, will be published as a regular issue of the journal Ultramicroscopy late in 1986.

The invited speakers (and their topics) were as follows:

D. J. Smith (High Resolution Electron Microscopy)

J. A. Eades (Convergent Beam Electron Diffraction)

D. B. Williams (X-Ray Energy Dispersive Spectroscopy in the Analytical Electron Microscope)

R. Gronsky (High Voltage Electron Microscopy)

J. M. Gibson (High Resolution Electron Microscopy of Interfaces and Surfaces) $M$. Rühle (Structure, Chemistry, and Diffusion Bonding of Metal/Ceramic Interfaces)

A. Heuer (Coherent Interfaces in Zirconia-Toughened Yttria-Zirconia Alloys)

A. Crewe (High Resolution Scanning

Transmission Electron Microscopy)

C. Colliex (Analytical Electron

Microscopy: Why are the Ultimate Limits of EELS yet Unforeseen?)

P. Batson (Detection of Local Changes in Bonding and Electronic Structure Using High Resolution EELS)

$O$. L. Krivanek (Design and Performance of a Parallel Detection EELS System) F. P. Ottensmeyer (Elemental Mapping with an Imaging Electron Spectrometer) L. E. Thomas (Microanalysis using Fine Probes)

N. J. Zaluzec (Intermediate Votage AEM;

Advantages Versus Disadvantages)

J. J. McCarthy (A Review of Spectral Artifacts in EDS)

L. E. Allard (High Resolution TEM

Imaging and Microanalysis of Supported Metal Catalysts)

J. M. Cowley (Subnanometer Diffraction) L. D. Marks (Profile Imaging of Surfaces) H. K. Birnbaum (Effect of Environmental Interactions on Deformation and Fracture of Solids)

P. R. Okamoto (Electron-Beam Induced Solute Redistribution in Alloys)

A group of companies specializing in electron microscope equipment jointly provided funding for the 20 invited speakers. Several other companies supported "Frontiers" by advertising in the program book or purchasing exhibit tables.

Many of the papers truly presented the "frontiers" of electron microscopy, includ-

continued 
ing new and exciting results from microscopes with sub-two Angstrom resolution, new schemes for parallel detection of EELS spectra, and applications of subnanometer diffraction. The great potential of imaging EELS spectrometers for materials science applications was also demonstrated.

Poster presentations played an important role in the conference, as evidenced by the selection of five outstanding posters for special presentation in an upcoming issue of Journal of Metals. These posters included: Z. C. Kang, L. Eyring, and D. J. Smith
(Dynamic Edge and Surface Processes in Terbium Oxide)

A. R. Pelton, F. C. Laabs, W. A. Spitzig, and $C$. C. Cheng (Microstructural Analysis of $\mathrm{I} n$-Situ $\mathrm{Cu}-\mathrm{Nb}$ Composite Wires)

Y. Lepetre, J. Murduck, E. Ziegler, and I. K. Schuller (Thin Films Observed by Microcleavage TEM)

T. Hsu and L. M. Peng (Experimental Studies of Atomic Contrast in Reflection Electron Microscopy)

W. T. Donlon, J. V. James, J. L. Bomback,
C. C. Wang, and C. R. Huo

(Characterization of Ion Implanted

Silicon; Correlation of Optical

Measurements with Microstructural

Observations)

The second conference on Frontiers of Electron Microscopy in Materials Science is expected to be held in the spring of 1988. Send suggestions for invited speakers and topics to Wayne E. King, Materials Science and Technology Division, Building 212, Argonne National Laboratory, Argonne, IL 60439.

\section{ON-SITE SHORT COURSES}

\section{conducted at your facilities or a nearby site}

The Materials Research Society has an expanding series of short courses, many of which are available to organizations on-site, depending upon the availability of the instructors.

The best way to keep your staff members on top of their fields is through an on-going program of continuing education. One of the most efficient, cost-effective methods is to bring experts to your geographical location to teach the latest techniques, discuss the newest research, and talk to your staff about the actual problems they face daily.

The economic savings of on-site programs are considerable, both in terms of time and budget. There are no travel fees or hotel costs for your staff, and attendees lose minimal time from their work.

MRS On-Site courses will be adapted to the specific needs of the sponsoring organization, and management will have an opportunity to interact with the instructor to discuss the course emphasis. Written requests from organizations will be handled on a first-come, first-served basis.

Some of the courses listed will also be offered at the 1986 MRS Fall Meeting. December 1-6, 1986 at the Boston Marriott Hotel/Copley Place in Boston, Massachusetts.

Application of Reflection Electron Diffraction to

Epitaxial Growth

Liquid Phase Epitaxy Techniques

Molecular Beam Epitaxy

Vapor Phase Epitaxy

Film Formation, Adhesion and Surface Preparation

Films and Coatings for Science and Technology

Properties of Films and Coatings

Plasma Etching for Microelectronic Fabrication

Plasma Enhanced CVD of Thin Films for Microelectronics

Deep Level Transient Spectroscopy

Emerging Ion Beam Processes for Materials Modification

Fractals in Materials Science

Sol Gel Processing of Glass

Surface and Thin Film Analysis

Ion Implantation, Defects, Diffusion and the Implications to

Device Processing

introduction to Transmission and Analytical

Electron Microscopy
Physical and Electrical Characterization of Semiconductors Introduction to Ceramic and Metal Matrix Composites

Electronic Properties of Amorphous Semiconductors

Modern Materials Analysis Techniques

Experiment Strategies for Process Variables

Safety Considerations for the Semiconductor Clean Room

Contamination Control for the Microelectronics Industry

Technology and Metallurgy of Fusion Welding

Design and Application of Vacuum and Plasma Processing Systems

Computer Assisted X-Ray Diffraction Analysis

Materials Aspects and Recent Advances of Silicon

Device Processing

Processing-Microstructure-Mechanical Properties in Metals

Materials Aspects of Microelectronic Packaging

Applications of Microprocessors to Equipment Interfacing and Process Control

For further details of courses available on-site or at the MRS Fall Meeting, write or call:

Vivienne Hawwood Mattox

MRS Short Course Manager

Materials Research Society

440 Live Oak Loop

Albuquerque, NM 87122

1505) 294-9532 